\title{
Tamoxifen and the role of oestrogen in the timing of parturition in the rat
}

\author{
Sandra J. Downing, D. G. Porter and D. W. Lincoln \\ Department of Anatomy, The Medical School, University Walk, Bristol BS8 ITD, U.K.
}

\begin{abstract}
Summary. After tamoxifen treatment 'spontaneous' pressure cycles were resumed in conscious rats in which myometrial activity had been inhibited with oestradiol benzoate, demonstrating an anti-oestrogenic effect of this compound.

Tamoxifen did not shorten the length of pseudopregnancy to less than 11 days when administered to rats 4 days after cervical stimulation. The effect of oestradiol benzoate (OB) treatment of pregnant rats depended on the day of administration. On Day $18 \mathrm{OB}$ injection $(5 \mu \mathrm{g})$ advanced the mean time of parturition by $5-6 \mathrm{~h}$ $(P<0.001)$ whereas injection on Days 19 or 20 delayed delivery by more than 6.5 and $8.5 \mathrm{~h}$ respectively $(P<0.05)$. It is suggested that the ability of tamoxifen given on Days 20 or 21 to advance the time of parturition in rats is due to its anti-oestrogenic activity.
\end{abstract}

\section{Introduction}

There is good reason to believe that oestrogen is essential for normal parturition in rats (Csapo, 1969; Catala \& Deis, 1973) but the part it plays remains unclear. Females ovariectomized on Day 20 do not litter but the administration of at least $5 \mu \mathrm{g}$ oestradiol benzoate soon after removal of the ovaries permits parturition (Catala \& Deis, 1973). Although high doses of oestrogen appear to advance parturition when given on Day 21, they delay delivery if given on Day 20 (Dukes, Chester \& Atkinson, 1974).

Treatment of pregnant rats with the anti-oestrogen tamoxifen (1-[4-(2-dimethylaminoethoxy)phenyl]trans-1,2-diphenyl-1-butene) on Day 20 or 21 of pregnancy advanced parturition by some $10 \mathrm{~h}$ (Lincoln \& Porter, 1979). The mechanism of action of tamoxifen could be (i) an anti-oestrogenic effect, perhaps interrupting the steroid-induced myometrial quiescence (Fuchs, 1974, 1976; Downing, Lye, Bradshaw \& Porter, 1978) and thereby inducing premature delivery; (ii) a luteolytic effect resulting in an accelerated decline in progesterone titres; or (iii) an oestrogenic effect (Harper \& Walpole, 1966; Jordan, Collins, Rowsby \& Prestwich, 1977) pre-empting the rise in oestrogen titres which normally occurs on Day 22 (Yoshinaga, Hawkins \& Stocker, 1969; Labhsetwar \& Watson, 1974; Lincoln \& Porter, 1979). We report here the results of experiments designed to explore the mechanism by which tamoxifen advances parturition.

\section{Materials and Methods}

Female Wistar rats from the closed Departmental colony at Bristol University were used throughout and were allowed Oxoid breeding diet and tap water, ad libitum. The animals were housed in light-controlled rooms and exposed to $14 \mathrm{~h}$ light (centred on 12:00 $\mathrm{h}$ noon GMT) $/ 24$ h. 


\section{Intrauterine pressure recording}

Ten rats $(250-300 \mathrm{~g}$ body weight) were anaesthetized and bilaterally ovariectomized, and each was equipped with an intrauterine balloon, 1 day post partum, as described previously (Downing et al., 1978). After $48 \mathrm{~h}$ the animals were connected via the balloon catheters to Statham, or Bell and Howell, pressure transducers for continuous intrauterine pressure recordings with a Grass $7 \mathrm{C}$ polygraph or a Devices $\mathrm{MX} 2$ pen recorder. The animals were allocated to one of two groups after $24 \mathrm{~h}$.

The 5 rats in Group 1 received 3 injections of $5 \mu \mathrm{g}$ oestradiol benzoate (Sigma Chemical Co. Ltd, London) s.c. in $0.05 \mathrm{ml}$ corn oil, $12 \mathrm{~h}$ apart.

The 5 rats in Group 2 were given 3 injections of $5 \mu \mathrm{g}$ oestradiol benzoate s.c. in $0.05 \mathrm{ml}$ corn oil, $12 \mathrm{~h}$ apart, followed by $250 \mu \mathrm{g}$ tamoxifen s.c. in $0.1 \mathrm{ml}$ corn oil, $1 \mathrm{~h}$ after the last oestrogen injection.

Intrauterine pressure was monitored continuously for a further $48 \mathrm{~h}$ after treatment. Recordings were analysed in terms of frequency, maximum amplitude of pressure cycles, and the total period of uterine quiescence per hour. These parameters were compared statistically between the two groups by using Student's $t$ test.

\section{Pseudopregnant rats}

Fifteen rats (200-250 g body weight), maintained under standard lighting conditions, which had undergone a minimum of 2 consecutive normal oestrous cycles, as revealed by daily vaginal lavages, were subjected to cervical stimulation by an electric vibrator on the evening of pro-oestrus. The animals were assumed to be pseudopregnant if a dioestrous smear was obtained on Day 4 after cervical stimulation. Rats exhibiting such a smear were allocated at random to two groups: the 8 rats in Group 3 received $250 \mu \mathrm{g}$ tamoxifen s.c. in $0.1 \mathrm{ml}$ corn oil on Day 4 after cervical stimulation, and the 7 rats in Group 4 received $0.1 \mathrm{ml}$ corn oil only on Day 4 .

The existence of pseudopregnancy in Groups 3 and 4 was determined by daily vaginal lavage for 8 days after treatment; the occurrence of a pro-oestrous smear being taken as the end of pseudopregnancy.

\section{Parturition study}

Multiparous rats (200-350 g) were placed singly with males of proven fertility on the night of pro-oestrus. The day on which a vaginal plug was found and spermatozoa identified in the vaginal smear was designated Day 1 of pregnancy. The mated animals were caged in groups of 10 for 16 days, and then housed individually in cages containing suitable nesting material. The standard lighting regimen was maintained throughout the experiment. On Day 18 the rats were allocated at random to a treatment group. Injections were given s.c. in $0.05 \mathrm{ml}$ corri oil at 12:00 h (noon). Rats in Groups $5(\mathrm{~N}=38)$ and $6(\mathrm{~N}=30)$ received oil only on Days 21 and 19 respectively. Rats in Groups $7(\mathrm{~N}=32), 8(\mathrm{~N}=32), 9(\mathrm{~N}=29)$ and $10(\mathrm{~N}=37)$ received $5 \mu \mathrm{g}$ oestradiol benzoate on Days $18,19,20$ and 21 respectively. The animals were inspected for evidence of parturition every $2 \mathrm{~h}$ from $06: 00 \mathrm{~h}$ on Day 22 to 19:00 h on Day 23, with as little disturbance as possible.

At approximately $6 \mathrm{~h}$ after delivery each mother and her young were weighed and the number of young (both alive and dead) in each litter was determined. Mean litter size and the litter weight were calculated and compared by means of Student's $t$ test. The distributions of births among the groups were compared by the Kolmogorov-Smirnov two-sample test (two-tailed analysis) (Siegel, 1956). 


\section{Results}

\section{Intrauterine pressure recording}

Oestrogen treatment reduced the frequency of intrauterine pressure cycles to minimum levels in all animals by $24 \mathrm{~h}$ after the first injection of oestradiol benzoate as described previously (Downing et al., 1978). Myometrial activity remained low in Group 1 animals for the remainder of the recording period (48 h) (Text-fig. 1). However, in Group 2 animals, the frequency of intrauterine pressure cycles increased following the injection of tamoxifen so that, by $11 \mathrm{~h}$ after treatment, it was significantly greater than the frequency of pressure cycles recorded from Group 1 rats $(P<0.05)$. The frequency of pressure cycles in tamoxifen-treated animals continued to rise, and a maximum frequency of 47 cycles/h was reached by $35 \mathrm{~h}$ after tamoxifen administration compared with 17 cycles/h in Group 1 rats $(P<0.001)$.

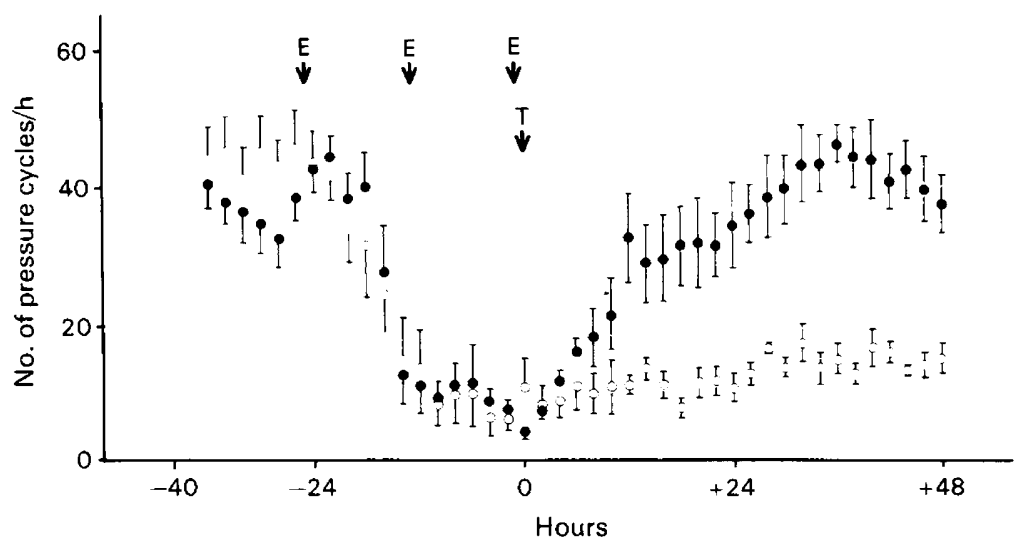

Text-fig. 1. Changes in frequency of intrauterine pressure cycles recorded from unrestrained rats from $36 \mathrm{~h}$ before up to $48 \mathrm{~h}$ after treatment with oestradiol benzoate (E) ( $5 \mu \mathrm{g} \mathrm{s.c.)} \mathrm{(O)} \mathrm{alone} \mathrm{or}$ oestradiol benzoate + tamoxifen $(\mathrm{T})(250 \mu \mathrm{g}$ s.c.) (O). Values are mean \pm s.e.m. for 3 rats in each group.

Myometrial quiescence, which reflected the changes observed in the frequency of pressure cycles, fell to a mean of $32 \mathrm{~min} / \mathrm{h}$ by $11 \mathrm{~h}$ after tamoxifen treatment (Group 2) compared to a mean of $49 \mathrm{~min} / \mathrm{h}$ in Group 1 rats $(P<0.05)$ (Text-fig. 2). By $36 \mathrm{~h}$ after tamoxifen the myometrium was continuously active (Text-fig. 3 ).

Maximum amplitude of pressure cycles did not change significantly after oestrogen treatment in either group of animals, but rose after tamoxifen treatment so that at $+17 \mathrm{~h}$ it was significantly higher than in oestrogen-treated controls (Group 1$)(P<0.05)$ (Text-fig. 2).

\section{Pseudopregnant rats}

All the animals subjected to cervical stimulation showed dioestrous smears for the 8 days following either corn oil or tamoxifen administration, i.e. both groups of animals experienced pseudopregnancies of at least 11 days' duration.

\section{Parturition study}

Groups 5 and 6. Control rats delivered young on either Days 22 or 23 between 06:00 and 18:00 h GMT. The delivery pattern was bimodal in both groups and skewed, as previously described for this colony (Lincoln \& Porter, 1976), with the first peak occurring between 10:00 and 14:00 h (Day 22) (Text-fig. 4) and the second, much smaller, peak occurring at about 10:00 


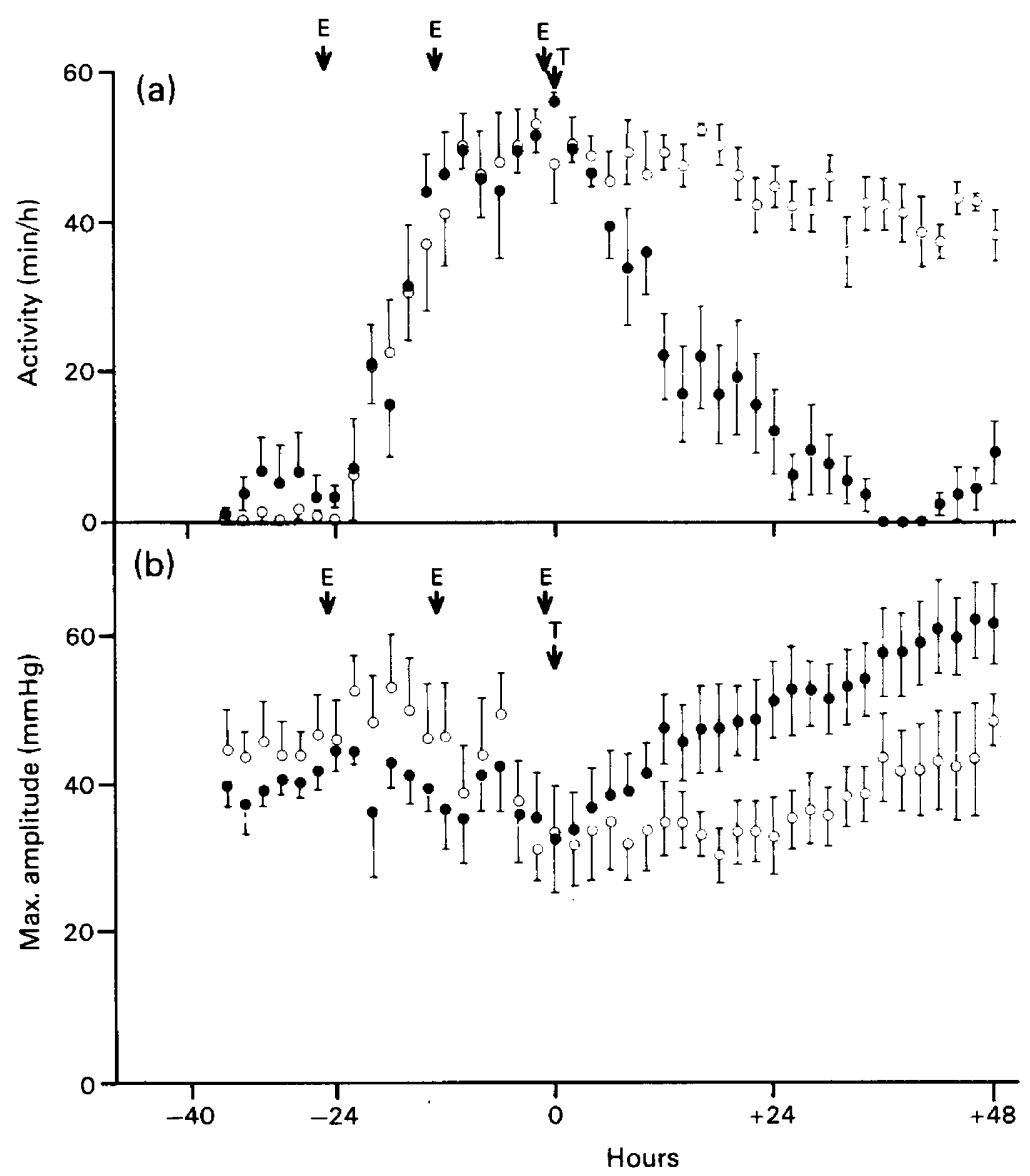

Text-fig. 2. Changes in (a) periods of uterine quiescence and (b) mean maximum amplitude of intrauterine pressure cycles in rats before and after oestradiol benzoate $(E)$ alone $(O)$ or oestradiol benzoate + tamoxifen $(T)(O)$. Values are mean \pm s.e.m. for 3 rats in each group.

h (Day 23). Mean delivery times were 18:26 h (Group 5), 17:24 h (Group 6) and the median time was 12:00 $\mathrm{h}$ for both groups.

Groups 7-10. Rats treated with oestradiol benzoate on Day 18 of pregnancy (Group 7) delivered early at a mean time of $11: 37 \mathrm{~h}$ on Day 22, and a median of 08:42 h on Day 22 $(P<0.001)$ (Text-fig. 4). Only one rat in this group gave birth on Day 23.

Treatment with oestradiol benzoate on Day 19 (Group 8) or Day 20 (Group 9) was followed by a significant delay in the mean and median times of delivery: mean times were $00: 34 \mathrm{~h}$ on Day 23 in Group 8 and 02:44 h on Day 23 in Group 9, and median times were $04: 34$ h on Day 23 (Group 8) and 06:00 h on Day 23 (Group 9). These times were significantly different from the values for Group 5 and $6(P<0.05)$.

Rats in Group 10 had a mean delivery time of $13: 24 \mathrm{~h}$ on Day 22 and a median time of 10:22 h on Day 22; these did not differ significantly from control values (Groups 5 and 6).

The incidence of dystokia $(6 \cdot 3-8 \cdot 1 \%)$ and of stillbirths $(3 \cdot 1-4 \cdot 2 \%)$ was similar in all groups. Mean litter size and weight showed no significant differences among the 5 groups and all the young appeared to have sucked normally since milk could be seen in their stomachs at inspection $6 \mathrm{~h}$ after birth. 


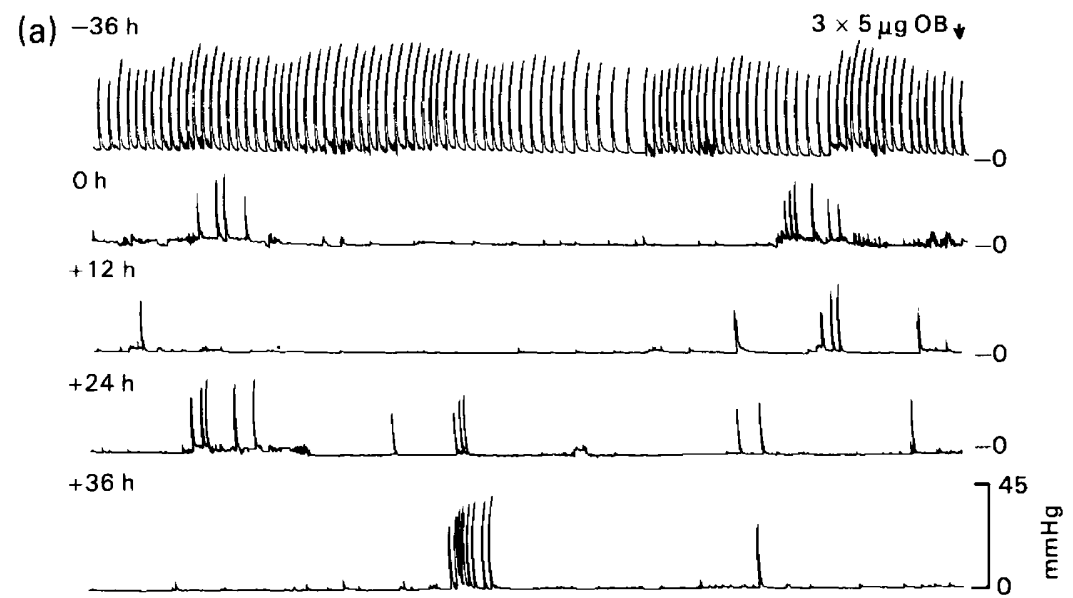

$1 \mathrm{~h}$

(b)

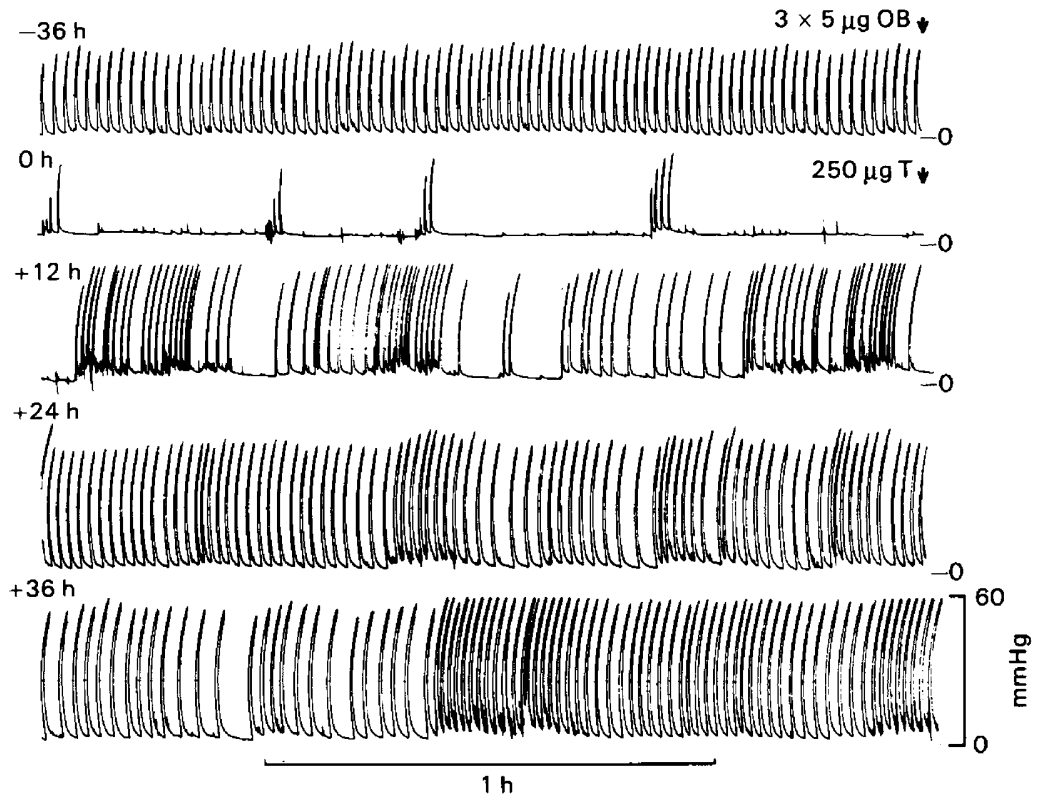

Text-fig. 3. Intrauterine pressure record from (a) a rat treated with oestradiol benzoate (OB) only and (b) a rat receiving also $250 \mu \mathrm{g}$ tamoxifen (T) s.c. at $0 \mathrm{~h}$. In (a) there is almost complete loss of 'spontaneous' pressure cycles by $36 \mathrm{~h}$ and the absence of recovery for a further $36 \mathrm{~h}$. In (b) the periods of quiescence are markedly reduced at $+12 \mathrm{~h}$ and they are absent at +24 and $+36 \mathrm{~h}$.

\section{Discussion}

The results of treating pregnant rats with oestrogen cast doubt upon the possibility that tamoxifen advances parturition by an oestrogenic effect. Although Lincoln \& Porter (1979) advanced parturition by giving tamoxifen on Days 20 or 21 , in the present study oestrogen treatment on Day 20 delayed parturition, and on Day 21 had no effect. Treatment with oestradiol on Day 20 or on Day 19, when tamoxifen injections led to earlier littering, resulted in a delay of parturition, a finding in agreement with the earlier report of Dukes 


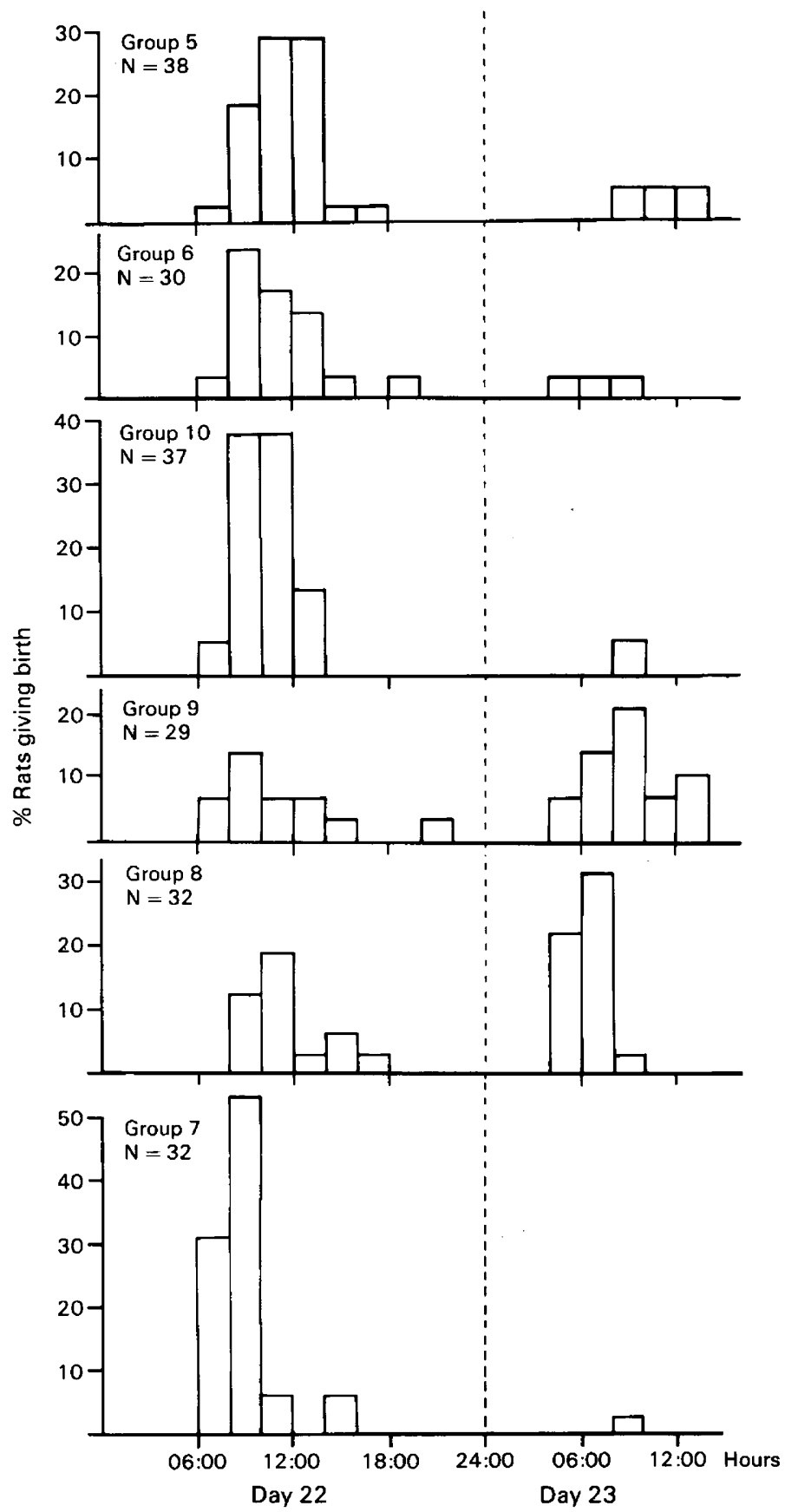

Text-fig. 4. Histograms depicting the frequency of littering between 06:00 h on Day 22 and 12:00 h on Day 23 in rats in Groups 5, 6, 7, 8, 9 and 10.

et al. (1974). If the tamoxifen effect was attributable to the oestrogenic properties of the substance (Harper \& Walpole, 1966; Jordan et al., 1977) then oestradiol should have mimicked its effect. It is difficult to account for the delay caused by oestrogen injections on Days 19 or 20, but one possibility is that if the normal pre-partum oestrogen surge is under feedback control the 
injections may have pre-empted this feedback mechanism and temporarily suppressed the oestrogen surge.

The failure of oestradiol to affect the delivery pattern when administered on Day 21 may have been due to coincidence of the effects of the exogenous oestrogen with the normal endogenous pre-partum surge (Yoshinaga et al., 1969; Labhsetwar \& Watson, 1974; Lincoln \& Porter, 1979). It is not clear why our results differ from those of Dukes et al. (1974) who found that injection of oestrogen on Day 21 advanced parturition, but Dukes et al. (1974) used larger doses and their rat colony had a different profile for normal deliveries. Administration of oestradiol as early as Day 18 on the other hand may have permitted the steroid to act and to be cleared from the circulation without affecting the timing of the endogenous surge. However, it is possible that such treatment would nevertheless enhance the oestrogen receptor population of target tissues, including the myometrium. Since these receptors apparently have a half-life of 5-6 days (Sarff \& Gorski, 1971), their concentration may have remained high until at least Day 22 when endogenous oestrogen titres themselves become elevated. An effect of oestrogen upon its prematurely sensitized target tissues thus would be facilitated.

It is also unlikely that tamoxifen advanced parturition through a luteolytic action because the drug had no apparent effect on the duration of pseudopregnancy as judged from vaginal smears. However, the possibility that the corpora lutea of late gestation are more susceptible to a luteolytic action than are those of early pseudopregnancy could not be excluded.

The third possibility, that the action of tamoxifen was attributable to its anti-oestrogenic effects is strengthened by the clear demonstration that it is able to reverse the inhibitory action of oestradiol-17 $\beta$ on myometrial activity. Downing \& Porter (1978) obtained evidence that an RNA-dependent protein synthetic step was involved in oestrogen inhibition of the myometrium and it is likely that tamoxifen blocks this step by competition with cytoplasmic receptors for oestrogens (Jordan \& Koerner, 1975; Furr, Valcaccia \& Challis, 1976). The time course of the tamoxifen reversal is consistent with this view.

Whether the effect of tamoxifen in advancing parturition (Lincoln \& Porter, 1979) is attributable to interference with the myometrial action of oestrogen is not known and resolution of this problem must depend upon a clearer understanding of the true role of oestrogen in parturition. Although such a possibility could lead to an advancement of parturition, the view is complicated by the likelihood that tamoxifen would interfere in other actions of oestrogens, such as the production of oxytocin receptors, the improvement of myometrial co-ordination (Downing et al., 1978) and the creation of conditions favouring oxytocin release, which are themselves assumed to favour the onset of parturition (Porter, 1979).

It is therefore suggested that tamoxifen does not advance parturition in rats by an oestrogenic or a luteolytic mechanism but probably though an anti-oestrogenic action. At present interference in the inhibitory action of oestrogen on the myometrium seems the most likely action, pre-disposing to premature evolution of myometrial activity and consequently the early onset of parturition.

The work was supported by an Agricultural Research Council grant (AG 7/77) and S.J.D. gratefully acknowledges a Lalor Fellowship. We thank Dr B. Furr, ICI Ltd, Cheshire, for a generous gift of tamoxifen.

\section{References}

Catala, S. \& Deis, R.P. (1973) Effect of oestrogen upon parturition, maternal behaviour and lactation in ovariectomized pregnant rats. $J$. Endocr. 56, 219225.

Csapo, A. I. (1969) The luteo-placental shift, the guardian of prenatal life. Postgrad. Med. J. 45, $57-64$.
Downing, S.J. \& Porter, D.G. (1978) Evidence that inhibition of myometrial activity by oestradiol in the rat is mediated by an RNA synthetic pathway. $J$. Endocr. 78, 119-124.

Downing, S.J., Lye, S.J., Bradshaw, J.M.C. \& Porter, D.G. (1978) Rat myometrial activity in vivo: effects of oestradiol-17 $\beta$ and progesterone in relation to the Downloaded from Bioscientifica.com at 04/26/2023 01:19:33AM via free access 
concentration of cytoplasmic progesterone receptors. J. Endocr. 78, 103-117.

Dukes, M., Chester, R. \& Atkinson, P. (1974) Effects of oestradiol and prostaglandin $F_{2 \alpha}$ on the timing of parturition in the rat. J. Reprod. Fert. 38, 325-334.

Fuchs, A.-R. (1974) Myometrial response to prostaglandin, enhanced by progesterone. Am. J. Obstet. Gynec. 118, 1093-1098.

Fuchs, A.-R. (1976) Influence of oestrogen and progesterone on uterine motility reassessed. Gynec. Invest. 7, 99.

Furr, B.J.A., Valcaccia, B. \& Challis, J.R.G. (1976) The effects of Nolvadex on pregnancy in rabbits. $J$. Reprod. Fert. 48, 367-369.

Harper, M.J. \& Walpole, A.L. (1966) Contrasting endocrine activities of cis and trans isomers in a series of substituted triphenylethylenes. Nature, Lond. $212,87$.

Jordan, V.C. \& Koerner, S. (1975) Inhibition of oestradiol binding to mouse uterine and vaginal oestrogen receptors by triphenylethylenes. J. Endocr. $39,193$.

Jordan, V.C., Collins, M.M., Rowsby, L. \& Prestwich, G. (1977) A monohydroxylated metabolite of tamoxifen with potent antioestrogenic activity. $J$. Endocr. 75, 305-316.
Labhsetwar, A.P. \& Watson, D.J. (1974) Temporal relationship between secretory patterns of gonadotrophins, estrogens, progestins and prostaglandin $\mathrm{F}$ in periparturient rats. Biol. Reprod. 10, 103-110.

Lincoln, D.W. \& Porter, D.G. (1976) Timing of the photoperiod and the hour of birth in rats. Nature, Lond. 260, 780-781.

Lincoln, D.W. \& Porter, D.G. (1979) Photoperiodic dissection of endocrine events at parturition. Anim. Reprod. Sci. 2, 97-115.

Porter, D.G. (1979) The myometrium and the relaxin enigma. Anim. Reprod. Sci. 2, 77-96.

Sarff, M. \& Gorski, J. (1971) Control of estrogen binding protein concentration under basal conditions and after estrogen administration. Biochemistry, N.Y. 10, $2257-2563$.

Siegel, S. (1956) The Kolmogorov-Smirnov Two Sample Test. In Non-Parametric Statistics for the Behavioral Sciences, pp. 127-136. McGraw Hill Book Co., New York.

Yoshinaga, K., Hawkins, R.A. \& Stocker, J.F. (1969) Estrogen secretion by the rat ovary in vivo during the estrous cycle and pregnancy. Endocrinology 85, 103-112.

Received 22 October 1980 